Professor and Dr Illingworth comment:

We thank Dr Shield for his comment on our paper ${ }^{1}$ concerning the section on 'normal' toe walking. Editors of journals have an annoying, yet justified way of demanding brevity, and brevity has its dangers. We are aware of the possible causes of toe walking and one of us has listed the following: ${ }^{4}$ normal toe walking in the preterm baby who has reached 'term' (not strictly toe walking except in the walking reflex), the normal, common toe walking of toddlers, spastic cerebral palsy, congenital shortening of the Achilles tendon, dystonia musculorum deformans, autism, Duchenne muscular dystrophy, peroneal muscular atrophy, spinal cord tumour, and shortening or apparent shortening of a leg (for example unilateral congenital dislocation of a hip).

The difficulty we all have is that of deciding at what stage we should investigate. We would not agree that every toe walker without obvious physical signs should have a CPU or other investigation. It would certainly be sensible to investigate a toe walker who had no abnormal signs but was late in developmental milestones as are many or most children with Duchenne muscular dystrophy.

References

${ }^{1}$ Illingworth CM, Illingworth RS. Mothers are easily worried. Arch Dis Child 1984;59:380-4.

${ }^{2}$ Firth MA. Diagnosis of Duchenne muscular dystrophy: experiences of parents of sufferers. Br Med J 1983;286:700-1.

3 Crisp DE, Ziter FA, Bray PF. Diagnostic delay in Duchenne's muscular dystrophy. JAMA 1982;247:478-80.

${ }^{4}$ Illingworth RS, ed. Common symptoms of disease in children. 8th ed. Oxford: Blackwell Scientific, 1984:239-41.

\section{Neonatal death-the neglected side of neonatal care?}

Sir,

Parents at the neonatal unit at St George's Hospital, Tooting are fortunate in having Drs McIntosh and Eldridge $^{1}$ leading the professional team. They show very clearly and sensitively the changes which have occured in the last decade or so in our approach and practice in handling death and dying in the newborn period.

As any paediatrician or nurse knows, the task is unenviable, demanding considerable personal fortitude as well as time and availability. The ability to cope is not easily acquired. Once we allow ourselves to become aware, we can learn what is involved and needed and help others with whom we work likewise. There are those more suited to this work than others and they can become the 'identified' people in the department. But neonatal death is only half the issue, the other being stillbirth. While it could be argued that bereaved parents after a stillbirth are the domain of the obstetrician and the midwife and not the paediatrician, he understands the symptoms of the child and parents. An increasing number have, like Drs McIntosh and Eldridge, become involved. It is indicative of the changes that have occurred in the last decade that the Royal College of Obstetricians and Gynaecologists has set up a working party to produce guidelines for the management of perinatal death by obstetricians. Likewise the Royal College of Midwives is examining how midwives can be instructed to help parents whose baby dies.
The booklet 'The Loss of your Baby', since it was first produced in 1979 continues to issue 50000 copies a year. The Stillbirth and Neonatal Death Society (SANDS) is an ever growing self help organisation with over 100 groups up and down the country. ${ }^{2}$ Esther Rantzen in her recent television programme 'The Lost Babies' brought home the tragic poignancy of the avoidance by professionals of the needs of bereaved parents. Paediatricians have a vital role to play in this field, not only to try and relieve human suffering but to prevent the harmful effects on families and children in their emotional growth and development, which can be so adversely affected by undealt with grief and mourning. ${ }^{3}$

\section{References}

${ }^{1}$ Mclntosh M, Eldridge C. Neonatal death-the neglected side of neonatal care? Arch Dis Child 1984;59:585-7.

2 Stillbirth and Neonatal Death Society (SANDS). Argyle House, 29/31 Euston Road, London NW1 2SD. Phone (01) 8332851.

${ }^{3}$ Bourne S, Lewis E. Pregnancy after stillbirth or neonatal death. Lancet 1984;ii:31-33.

DAVID MoRris

1 Bryancton Square, London WIA $4 F E$

\section{Microcomputers and malformation syndromes}

Sir,

We read with great interest Winter and Baraitser's annotation on malformation syndromes, ${ }^{1}$ and we agree totally with their views that paediatricians should now learn to use microcomputer technology.

Microcomputers are already able to establish a ranked differential diagnosis in human malformation patterns. In fact, we have developed such a programme in the Department of Paediatrics and Genetics at the Geneva University Hospital.

Syndroc (the programme's name) is built on three different approaches. The initial differential diagnosis is given by a pseudo-Bayesian algorithm. In the heuristic approach, Syndroc looks for the presence or absence of the pivot signs, not introduced primarily, of each proposed diagnosis. This approach permits a refined diagnosis. The computerised descriptive method allows the storage of undiagnosed cases. Ideally the boolean comparison of those cases should permit, in the future, the recognition of new dysmorphic entities. The programme is written in PL/I-80 with the support of a database (MDBS III). It runs on a microcomputer working with the $\mathrm{CP} / \mathrm{M}$ monitor control programme.

A first retrospective study based on 100 cases has shown an agreement of $95 \%$ between the geneticist's diagnosis and the two first diagnoses of Syndroc.

We would also like to point out the didactic advantage of such a programme. Our experience has shown that repeated use of Syndroc, either on real or fictitious cases, seems to improve the user's diagnostic accuracy.

\section{Reference}

${ }^{1}$ Winter RM, Baraitser M. Malformation syndromes-a diagnostic approach. Arch Dis Child 1984;59:294-5.

Daniel Schorderet and Patrick Aebischer Geneva University Hospital, CH-1211 Geneve, Switzerland 